\title{
InSTRUCTIONAL MODEL DEVElopMENT FOR PAINTING
}

\author{
Tri Aru Wiratno ${ }^{1)}$, Diana Nomida Musnir²), Atwi Suparman ${ }^{3)}$ \\ ${ }^{1)}$ Universitas Negeri Jakarta, Jakarta, Indonesia \\ E-mail: triaruwiratno@yahoo.co.id \\ ${ }^{2)}$ Universitas Negeri Jakarta, Jakarta, Indonesia \\ E-mail:diana.nomida@unj.ac.id \\ ${ }^{3)}$ Universitas Terbuka, Tangerang Selatan, Indonesia \\ E-mail:atwi.suparman@unj.ac.id
}

\begin{abstract}
Students can paint by developing ideas and ideas through deductive and constructive learning. Painting subject is a subject that is synonymous with learning painting skills. The technical mastery of painting is based on one's talent in the learning process of painting. Painting well is a satisfaction for a painter. Students are required to have a soul of creativity and know themselves as whole individuals in their lives. To grow in a new awareness about what are the ideas of his work, we need a learning model. With deductive and constructivist learning models that provide space for everyone to grow and develop themselves in learning painting. Developing a learning model of painting to be better and more effective and structured in painting without reducing the power of expression in making paintings. The development model in this study uses the Dick and Carey Model and the research method uses the Borg and Gall model. The results of this study are in the form of a development model of learning to work in painting that can increase interest and rank and insight in the field of painting.
\end{abstract}

Keywords: Instructional Model; Art; Painting

\section{INTRODUCTION}

Painting classes at the Fine Arts Study Program at the Jakarta Art Institute, are subjects that identify by learning painting skills to master techniques and media or various types of media well and beautifully. But understanding and awareness of the concepts and methods of art. As an actualization and understanding of the value of art, from a high sense of imaging in building someone sensitive to the socio-cultural environmental problems of the surrounding community, so that they can see this life, more civilized in cultural diversity. National culture. Students are expected to have the ability and skills to become professional painters.

Students use existing patterns of learning to paint early as well as the lecturer as a place where they paint to be applied to students when they paint. This means that learning to paint is not to achieve the goal of learning to paint, with stages in the learning objectives. In other words, the current learning steps are more pressing learning material, good painting techniques, not based on effective and efficient learning models in painting. Thus the learning process must be understood in achieving the learning objectives effectively.

In the art college and upper secondary education in the learning model of painting just by pressing right on how to paint it into a work of art skills that have the beauty of form. The technical mastery of painting is based on a person's talent in the process of learning to paint to be able to paint in good form and to paint it as their satisfaction because they have expressed their desire. Painting becomes a form that achieves the value of beauty so that the only technical ability that stands out.

The contextual learning model uses concluding deductive learning, reading, and constructivist humanistic culture so that everyone learns with their own thought experiences. As a first step in learning to paint, to arrive at the awareness of seeing life as a social reality of a civilized society.

This research will result in the development of a model of painting learning that can be an alternative model of learning that exists today. For the sake of realizing this case, Lukan's creative development was enlarged and he recognized himself as a whole person in his life, to build and foster new self- 
awareness about what his ideas were. To get to the point of life that is the goal, as a step in making a painting, so that aware of the importance of painting has a concern for social life. According to Comte (2014: 73), the status of social science related to the logic of natural science, that is social phenomena, are natural facts that are bound to natural law. Likewise for Durkheim, an autonomous social reality is a structure in the sense of the individual that is influenced by the soul, collective consciousness, and moral rules. For Plato, works of art as mimetic forms or imitations of ideas and representations of absolutes. Absolute in Plato's thought is interpreted with a variety of understandings. One of them is as art that comes from Allah SWT. However, art has become a concept of beauty from a work of art. Before there was beauty in art, another beauty existed. This was said by Socrates as Plato's predecessor, that the beauty of a form is not because it is beautiful, but because it is the beauty itself that makes the work of art beautiful.

For this reason, the beauty of artworks departs from ideas that represent the essence of Allah. In essence, eternal beauty as meaning and thought in a belief. Who has the beauty itself is God. Allah is Most Beautiful and loves beauty as a paradigm that is in Islamic thought refers to the Holy Qur'an. What God created is a beauty, be it the beauty of natural scenes, humans, and animals. "We have indeed created man in the best form" (At Tiin: 4).

With deductive and constructivist learning models that provide space for everyone to grow and develop themselves in learning to paint. As an artistic awareness that has a noble purpose, not only mastering the technique of painting. Will bring itself to the uniqueness and self-awareness of the advantages and disadvantages. Making art into a field that is not just painting skills, but rather as the formation of humans through visual language.

\section{Methodology}

The purpose of this study is: (1) produce a design model of learning to work in painting; (2) produce learning materials for the Art course. The learning model development model in this study adopted the Dick and Carey model. Meanwhile, the research approach or method used uses the Borg and Gall model.

Borg and Gall define research and development as follows: Research and development is an industry based development model in which the findings of research are used to design new products and procedures, which then are systematically field tested, evaluated, and refined until they meet specified criteria of affectiveness, quality, or similar standards (Borg, 2007).

\section{RESULTS AND DISCUSSION}

The results of research on the development of painting models are the beginning of learning in painting courses, IKJ's pure art study program as a paradigm shift in the mind of art lecturers. Lecturers need knowledge of learning design as a basis for teaching gradually and continuously. The results of this model development study can be applied adaptively. As Ki Hajar Dewantara explained, art is all human actions arising from the life of their feelings and is beautiful so that art can move the souls of human feelings. Meanwhile, according to Soedarso (2012: 354), art is the work of humans who assume inner experiences; inner experience is presented to stimulate the emergence of inner experience also in other humans who live it. Its birth was not driven by a desire to fulfill basic needs but was an attempt to complete and perfect their human degree in meeting spiritual needs. For this reason, the learning process of painting in the past used a personal approach to the interest and desire to study painting with someone who can paint. Learning painting is done by making a painter as a teacher who teaches painting. Departing from such painting learning, painting education in Indonesia began with the establishment of the Indonesian Drawing Experts Association (Persagi), Young Indonesian Artists (SIM) pioneered by Sudjojono until the establishment of the Indonesian Academy of Fine Arts (ASRI) in Yogyakarta and at the Bandung Institute of Technology (ITB) whose art department is part of the Faculty of Architecture whose instructors are Dutch citizens Ries Mulder who teaches painting.

As such, the tertiary education for art built-in Indonesia followed the European education method-known especially through the MO (Middelbare Odnerwijs) style of schooling. In both Bandung and Yogyakarta, the art students were introduced to practical academism at the beginning of their education, as well as theoretical art history - this realty in Indonesia strengthened James Ellkin's thesis that art history is globally known (Supangkat, 2012: 122).

College-level fine arts education carried out in Indonesia follows a method of education developed in Europe known through MO (Middelbare Odnerwijs) education. Both in Bandung and Yogyakarta, art students were introduced by their academics in the field of practice at the beginning of their education. History of art in the field of theory in reality in Indonesia helped strengthen James Elkins's discovery that the history of art is known almost all over the world.

Same with the Jakarta Art Institute, the learning model is applied in the studio, sorogan, and imitates the teacher's painting style. The same is done by the world's great painters, known by the Atelier method as a form of teaching style as introduced by Gustave Moreau who taught Picasso, Braque, and other artists. A prospective artist is apprenticed to a professional artist while helping the artist with their work when they are painting. However, painting education at the Jakarta Institute of the Arts combines a more structured learning methodology system and a curriculum even though it is still simple. What was done during the leadership of Srihadi Soedarsono who still provides flexibility in learning to paint departing from his students? The teaching theory applied by Srihadi Soedarsono is deductive learning and humanistic constructivist.

The results of the research and development of this model can be used as a learning model to improve the ability of lecturers to teach art courses. One of the students at the end of the lecture held a joint exhibition as a good learning process to achieve effective and efficient learning in conveying learning 
objectives. In line with the development of learning materials, it is necessary to maintain the quality of art education and as a measurable evaluation of learning, both through the development of conceptual models of learning and procedural models to produce a model of teaching materials. The development model according to Gay, Mills, and Airasian is the development not to formulate or test theories, but to develop products that are effective for the use (Emzir, 2015: 263). The results of developing learning models will not be effective and efficient if they are not carried out following the learning development procedures. Borg and Gall (2007: 589) explained the development of an educational model that uses research findings in designing new products and procedures. Research models are systematically tested in the field, evaluated, and improved to obtain specific criteria about the effectiveness, quality, or the same standard.

Meanwhile, the understanding of the model according to Richey (2011: 8) is a model that implies a representation of reality presented with a degree of structure and order, and models are typically idealized and simplified views of reality. A model implies the reality of representation that is presented with a level of structure and order, and the model is usually a reality view that is realized and simplified. The model as a representation of the reality of the concept of learning forms identifies the problem to be developed. Thus, the concept of developing learning models is a form of the conceptual development of learning in a structured and systematic manner to achieve learning effectively and efficiently.

The learning model as a conceptual refers to learning and learning theories that are assembled with the learning design model. Learning theory is an explanation and definition that will be used as reference material to be able to understand the learning process well. Learning becomes a series of natural events learning process to achieve the goals expected by lecturers and students. This learning theory which becomes understanding refers to problems related to attitudes of change, understanding, freedom, and social awareness.

Learning is a relatively permanent change in a person's knowledge or behavior due to experience. This definition has three components: (1) the duration of the change is long-term rather than short-term, (2) the locus of the change is the content and structure of knowledge in memory or the behavior of learners, (3) the cause of the change is the learner's experience in the environment rather than fatigue, motivation, drugs, physical condition, or psychological intervention (Richey, 2011: 51-52).

Learning is a relatively permanent change in a person's knowledge or behavior due to experience. This definition has three components: (1) the duration of change is the long term, not the short term, (2) the locus of change is the content and structure of knowledge in the memory or behavior of students, (3) the cause of change is the experience of students in the environment rather than fatigue, motivation, drugs, physical conditions, or psychological interventions.

Learning in the context of education is related to finding knowledge so that someone can understand what they want to get. However, according to Gagne (1977) learning is a change in human disposition or capability that lasts for some time and which is not solely caused by the growth process.

Behavioral psychologists view learning as the ability to perform new behavior; they focus on a stimulus-response approach to learning (Richey, 2011: 52). Behavioral psychologists see learning as the ability to engage in their new behavior that focuses on a stimulus-response approach to learning.

Learning involves a cognitive change that is reflected in behavioral change, such as changing from not knowing to know the procedure for erasing a word in a word processing program. If there is no change, then no learning has occurred (Mayer, 2008: 7).

Learning involves cognitive changes that are reflected in changes in behavior, such as changing from not knowing to know the procedure for erasing a word in a word processing program. If there is no change, learning does not occur.

Cognitive theorists believe the learner's mental processes are the major factors in explaining learning. The ways that learners process and apply information change one's thoughts and internal mental structures (Richey, 2011: 56).

Cognitive theorists believe that a student's mental processes are a major factor in explaining learning. How students process and apply information change a person's internal thoughts and mental structure.

The theory of humanistic learning as a process of discovering itself or humanizing humans with all their potential. Achievement of this process is self-actualization, self-understanding, and self-realization of people who learn optimally (Anwar, 2017: 230).

In learning all aspects that exist in students are developed into a value and meaning of life for them. Learning is not just about thinking, having knowledge, and having skills, but also life experiences related to socio-cultural reality problems. Providing understanding and awareness of the value of truth is an attitude of change and concern for the socio-cultural reality of the community.

The expert's view of learning theory that has been explained becomes a reference in this study by using the principles of learning as an explanation. It can be seen that what is done by educators is based on research. With an approach to learning idealism, students learn the ideal form of art and art paintings.

The results of research and development in addition to producing learning models are also equipped with learning materials, guidelines for lecturers, and student guides to be used by lecturers and students in the lecture process. With this learning material, students understand the learning material being studied.

The concept of developing a learning model for working in art is the design or pattern used to shape the curriculum, plan then learn and guide, study, in painting engineering courses. In compiling science, it becomes a reason to learn to paint.

Enhance mind power. Learning is knowledge formed through humanist deductive and constructive reasoning, including knowledge about God. Making a painting mimics one of the attributes of God. Conceptual learning models and system models produce teaching material models. 
Social learning theory expands notions of learning by focusing on the impact of the social environment (Richey, 2011: 60). Social learning theory broadens the understanding of learning by focusing on the impact of the social environment.

The learning model that is carried out in a deductive and contextual approach is constructive, humanism is more inclined to the form of freedom. The theory of constructivism learning models is a systematic procedure in organizing learning experiences to achieve learning goals (Anwar, 2017: 356). Humanistic learning theory is learning that emphasizes how to humanize humans so that their potential can develop. The contextual learning model of learning as freedom in learning is an experience whose value exceeds learning outcomes which are usually the subject of experience and are usually the subject of the teacher's attention. From that experience, students can draw on the learning process that can lead to an internal appreciation in finding learning outcomes. Freedom may cause pain, suffering, or other negative things. However, in turn, through mistakes, through the process of "searching", students are expected to find out for themselves the truth, happiness, and things that are considered positive for them.

Richey (2011: 60) contributes to the socio-cultural environment of society. As a form of concern for students on the socio-cultural reality of the community.

By learning, all aspects that exist in students can be developed as a value and meaning of life for them. Learning is not just about thinking, having knowledge, and having skills, but getting life experiences related to socio-cultural reality problems. Providing understanding and awareness of the value of truth is an attitude of change and care for the socio-cultural reality of the community.

Painting in the learning of socio-cultural reality, according to Taft and Mayer as quoted by Sucitra (2011: 5), a painting that presents a picture that represents things that appear, ideas, everyday events, or perhaps those that have no direct connection to our own experiences. In other cases, we are often inspired, informed, and given pleasure by what we see. The painting is basically a two-dimensional picture that is painted on a flat surface. Generally, paintings are rectangular and hang flat against the wall.

According to Pringgadigdo, painting is a language of expression from artistic experiences or ideologies that use lines and colors, to express feelings, express emotions, movements, illusions, and illustrations of one's subjective conditions. The reference is to describe the two-dimensional plane of intent (Susanto, 2011: 241).

Art, for Walter Benjamin, is one of the expressions of a culture, not a part of a worldview, as in Goldman's understanding, not a totality as in Lukacs, but a fragment, a microcosm. Art has a material basis in the structure and organization of society, in its convictions, modes of production, and political arrangements. Until now, Benjamin's ideas are in line with the dominant view in modernism, that art is very closely related to the basis of its production. If nondemocratic art lies in monopolistic auras, for example, the typical languages of storytelling that mark the specialisms and expertise of bourgeois society, socialist art must be based on collective egalitarian forces shared in a modern society, facts realism (Jenks, 2013: 130-131).

Scheler believes that values are arranged in a priori hierarchical relationships. This must be found like values, even valid for unknown values. In the whole of reality, in value, there is only one hierarchical arrangement that constitutes all values which have their place. These values are as follows.

a. The value of Pleasure, in the lowest row, is pleasure preferred over displeasure.

b. Vitality or life value, the value of the sense of life that includes subtle, sublime, or soft to the rough or ordinary, also good as opposed to the bad. The value derived from here is welfare.

c. Spiritual Value, a value that does not depend on the entire physical environment and the surrounding natural environment. This level of value is higher than the two previous levels.

d. The Value of Chastity and Profession, the level of purity does not depend on the time difference and the difference in the person who carries it. Responses to values are usually manifested in believers and non-believers, amazed, and worshiped (Alfan, 2013: 92-93).

The model of learning materials for painting based on cultural reality is not only emphasized on technical ability in terms of skills. However, how the technical ability as a beginning to enter the real problem as understanding, awareness, analysis, synthesis, and creativity in painting. Then it will give birth to our values as human beings, as social and religious beings who can assemble the ability to become a better life glory.

According to Vygotsky, culture not only provides a setting for individual cognitive development. Culture provides cultural symbols (psychological devices) and children learn to think with this form of reasoning (Gredler, 2011: 396).

The expert's view of learning theory that has been explained becomes a reference in this study by using the principles of the learning model as an explanation. These things are as follows:

(1) Understanding, how students can learn to understand the material and learning objectives provided as a concept of knowledge in seeing the experience of socio-cultural reality into a form of painting through the transformation of knowledge and forms into a sign and symbol of a painting idea.

(2) Changes, how students when understanding the material and learning objectives well. In integrating art knowledge with life experiences in socio-cultural reality, there is a change in seeing problems related to learning. The deductive approach becomes the relevance of work experience. These changes will motivate learning, not mastering the material but achieving the learning objectives. However, learning as an attitude of this change becomes learning as a necessity of life in the socio-cultural reality that always wants to change and keep changing in making paintings. 
(3) Awareness, the learning process that leads to understanding and changing the way of thinking and the ability of technical skills to be mastered. The concept of art gives meaning in capturing the social and cultural reality into a work of "new" painting. Raising awareness of learning not only masters the material and learning objectives, but also how learning becomes an attitude and outlook on life in socio-cultural realities, where students in the community become catalysts.

(4) Freedom, with understanding, changes in thinking that give birth to awareness about learning make students feel the freedom in working. Freedom is a form of understanding, change, and awareness of thinking that is better and understand something good or not arranged in thoughts and views related to the life of the socio-cultural reality of society.

(5) Concern for socio-cultural reality problems arises from the learning process that provides a structured and conceptual understanding of learning and provides steps for change in looking at socio-cultural reality problems that refer to learning theory.

Learning models become part of the activities of planning the learning process in the world of education. For this reason, there are several views regarding learning. This learning theory is very supportive in seeing the learning problems in a study. With the hope that it will be understood the extent of the development of learning in the developing world of education and can meet the needs of the community.

Instructional development or instructional design is a systematic process of achieving instructional goals effectively and efficiently through identifying problems, developing strategies, and instructional materials, and evaluating the strategies and instructional materials to determine the things that must be revised. Using procedural models systematically in making it produce teaching materials.

Understanding of learning is oriented to how learning objectives are following what is achieved from learning outcomes as goals. As a pattern of thinking in a structured way to achieve learning to be achieved within a certain time. Thus, students can undergo the stages of learning well despite facing problems in learning.

Learning efforts must be designed using a system design. The design process must start from needs analysis, formulation of general objectives, and continue step by step to develop learning. After that, it is necessary to look for empirical evidence about the efficacy of learning so that improvements can be made to the learning material produced.

From several views about the definition of learning, the essence of the above understanding can be drawn. Learning is a series of plans and learning plans to be able to achieve the goals set so that the learning plan runs effectively and efficiently.

Theory level as a form of the conceptual framework can explain how the learning process runs well following the stages that are carried out as it should. Same as the learning models can provide possibilities by developing learning systems to be able to achieve learning objectives.
The design of learning painting in the socio-cultural reality as concepts and learning methods are arranged in teaching materials. Learning painting requires conceptual, procedural, and product models to be able to develop learning that has been running but has not used an effective and efficient learning model following the rules of education so far. This learning model can indeed be considered and can be implemented in a painting learning material. The following are various learning models, such as (1) Jerold Kemp's Instructional Design Model, (2) Dick and Carey's Instructional Design Model, (3) Glasser Model, (4) Gerlach and Elly Model, (5) Instructional System Development Procedure Model ( PPSI), (6) Teaching Research System Model, and (7) MPI Instructional Model M. Atwi Suparman.

\section{The Appropriateness of Learning Models}

Before learning material is considered feasible, there needs to be validation from experts with various abilities, such as painting material experts, instructional design experts, and graphic design experts. Individual Trial, Small Group Trial, and Revision.

The learning model as a product of development has been revised based on input from students in individual trials. Next, an evaluation was carried out with a small group of six people. The six people consisted of three students and three female students. Each person has an ability that is categorized as having normal, sufficient, and very good abilities. Based on the results of the validation carried out by the small group evaluation, there are inputs and suggestions by revising the learning model of the painting technique.

\section{Field Trials and Revision}

The learning model as a product of development has been revised based on input from students in small group trials. Next, an evaluation was carried out in a field test consisting of 15 students and students who had attended the Art Painting course.

According to the analysis, what needs to be improved is the teaching methodology because a good teaching methodology can improve the quality of students or students at IKJ, especially those students who study painting. Students must get the correct method from the beginning of lectures until they produce work proportionately and maturely. So, by giving assignments to students, it is necessary to base the material being taught, students are not released to search for themselves.

Based on the results of the validation carried out by carrying out field trials, some inputs and suggestions revising the learning model of painting techniques required a learning model that addresses the problem of painting techniques, as well as the introduction of materials in painting. It was enriched by providing knowledge about world painters, inspirational painters. The theme given must be related to the socio-cultural reality of life to be able to process it into a work that is related to material, themes, and freedom in choosing media. 
To achieve this learning goal, we can see from the developed in Table I. characteristics of the development model that will be

TABLE I

CHARACTERISTICS OF DEVElOPING ARTWORK LEARNING MODELS

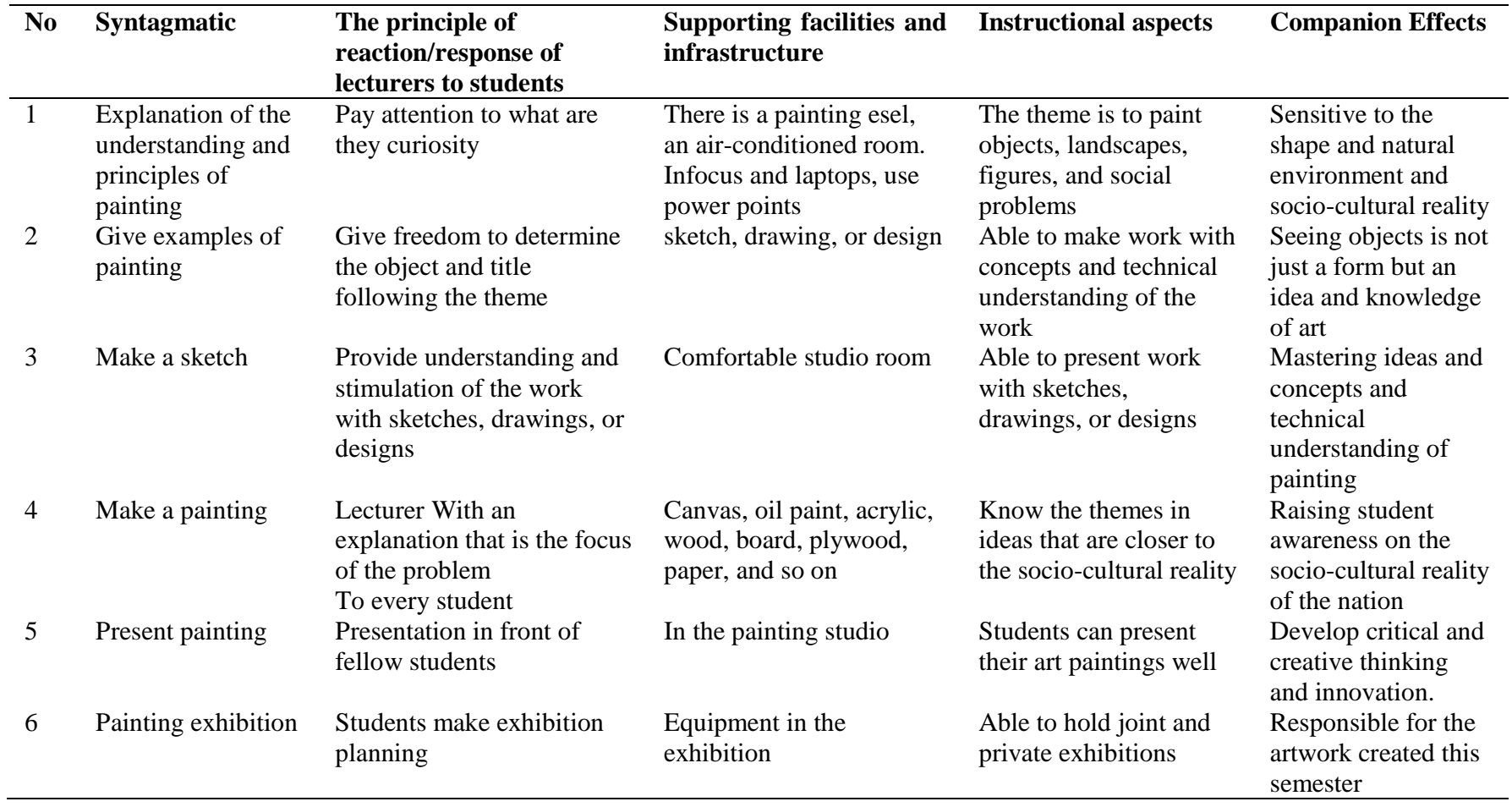

Based on the results of preliminary research analysis activities known. by conducting research and development of learning models that are equipped with learning materials and the steps as follows:

1. Identifying Learning Needs and Writing General Instructional Objectives (TIU)

Analysis of the need to find out what must be made to be able to determine the learning needs of painting following the learning objectives. To meet the lack of knowledge and skills of lecturers in learning, learning models and learning materials that will be used in learning activities need to be made. The results of the needs analysis are used to have a general-purpose lecture.

\section{Conduct Learning Analysis}

The analysis of learning activities is carried out to describe and describe general behavior into specific behavior that is structured logically and systematically.

\section{Identifying Student Behavior and Early Characteristics}

Behaviors and initial characteristics of students who are the subjects in this study are as follows.

a. The level of ability possessed by Fine Arts students is quite good.

b. The mastery of the media owned by Fine Arts students who take Art courses is quite good.

c. The art knowledge possessed by Fine Arts students is quite good.
4. Write Specific Instructional Purposes

The results of the elaboration and explanation of general learning objectives become specific instructional objectives showing the following types of competencies.

a. If given the freedom to choose the phenomenon of sociocultural reality in their respective lives, students can describe ideas and creativity in working at least $80 \%$ of painting properly and correctly.

b. If asked to write the basic concepts of fine art, painting, students can describe the basic concepts of fine art contained in the painting at least $80 \%$ properly and correctly.

c. If asked to make a concept of art painting of socio-cultural reality, students can describe the concept of socio-cultural reality in a minimum of $80 \%$ good and correct painting.

d. If asked to interpret the nature of objects, figures, and the environment, students can make the meaning of a minimum of $80 \%$ of painting work properly and correctly.

e. If asked to use brushes and rough, soft, and expressive stroking techniques in making a painting, a student can make a minimum of $80 \%$ of the artwork properly and correctly.

f. If asked to use the style of painting in painting, students can make a minimum of $80 \%$ of painting work properly.

g. If asked to practice using a variety of media in making paintings, students can make works of at least $80 \%$ of painting properly. 
h. If asked to interpret natural themes, figures, and environmental socio-cultural realities, students can make a minimum of $80 \%$ of their artwork properly and correctly.

i. If asked to describe how to present a work of painting, students can present a minimum of $80 \%$ of the art of painting properly and correctly.

j. If asked to arrange the elements of painting, students will be able to make works of art following their interests at least $80 \%$ properly and correctly.

$\mathrm{k}$. If given the freedom to practice painting, students can present a minimum of $80 \%$ of the artwork properly and correctly.

\section{Arranging the Appraisal Tool}

At this stage of lecturing, assessment tools are compiled in the form of artwork that is used to measure the level of mastery of the techniques, ideas, and art knowledge of Fine Arts students on behavior written in specific learning objectives. As explained by Suparman, the test results reflect the level of students' mastery of the competencies contained in the instructional objectives. This method of interpreting test results is called benchmark reference interpretation.

\section{Develop Learning Strategies}

When making learning strategies or lectures there are five activities, which are as follows.

a. Make a sequence of lecture activities, that is the sequence of learning activities as a lecturer in delivering the contents of lectures to students.

b. Outline the contents, that is the title of lecture content that is consistent with the order of learning objectives that refer to the competency map.

c. Creating instructional methods, that is the way of learning conducted by lecturers in organizing lecture material that will be delivered to students so that lecturing activities become effective and efficient.

d. Making learning media, that is instructional equipment and materials used in learning so that lecturers and students can carry out lecture activities following learning objectives.

e. Determine the learning time used to fit the learning material in each step of the lecture activities.

7. Developing Learning Models

Learning products developed in the form of learning materials as follows.

a. The learning model produces learning material containing lecture material based on learning objectives. The resulting competency map is outlined in the learning strategy as part of the structural learning step and as a step to achieving effective and efficient learning objectives.

b. Lecturer guidelines as a reference that provides direction for learning must be carried out; become the basis for determining or implementing learning because in it there is a learning strategy that is appropriate to the stages and steps are taken in the learning process. Learning steps that use the learning methods and media are contained in the lecturer guidelines so that lecture activities are well monitored and run following the learning strategies that are already contained in the lecturer guidelines.

c. Student manuals as a guide for students to guide students, in following the lecture process. All of that refers to learning material during lectures, both related to lecture material, assignments, and things that must be done during lectures. Following a predetermined schedule. Learning materials are developed based on learning strategies that are ready to be evaluated through formative evaluation (more is presented in appendix III).

\section{Formative Evaluation Results}

Evaluation is done by how many experts, can be appreciated by content experts that painting learning materials book is very necessary for pure arts students who take art courses. Same as learning design experts give appreciation by providing input following the needs of the painting. For the linguist section, the appreciation of the book for painting learning materials is very complete, by providing input related to language that is easier for students to understand. Evaluation with students one by one gives a good response because students need painting books as learning material from ongoing lectures. For small group evaluations using written questions they need to be related to painting, painters, and painting techniques, maybe the problem is to be able to buy the book to feel objections, that is because students' interest in reading is still lacking, and field evaluations are integrated into small groups because the painting students are still a little bit almost the same as a small group of 12 students.

The appropriateness of the learning material model for students as a basis for the concepts and methods of work carried out so that students can follow the process in lecturing activities, obtain the results of evaluations from art material experts 4.43 means that according to the very appropriate, while obtaining an evaluation of learning design experts 4.53 meaning relevant to approach very relevantly, for the acquisition of evaluations from linguists 4.18 meaning relevant to very relevant, as well as the acquisition of evaluations from graphic design experts 4.47 good meaning among the very good. Then the evaluations obtained from individuals 4 are good, while evaluations from small groups 4 are good, for field evaluations it is not possible because the limitations of students are equal to the number of small groups.

Based on the post-test results obtained by the value of 90 known to be an increase with the results of pretest 70 . This means that students have been able to master the concepts, techniques, and implement ideas in the art of painting he made. Thus the effectiveness of the learning model as a learning material can help students in making a structured painting and understand the stages in making the work. Although it has not been a concern so far, it will become more important in lectures in the future.

The development of this learning model is the beginning to make a paradigm shift in thinking for art colleges gradually as follows:

1. College of art gave birth to art graduates as artists who have the capacity of academics with artistic competence. Able to adapt to technological developments related to 
painting and master the concepts and methods of painting that are qualified. Able to take decisions and attitudes to art to provide alternatives and solutions and be responsible for what is done in making the work of painting an achievement.

2. Course learning is not only based on the ability of the lecturer as an artist but also based on the ability to design learning from the courses they teach. Besides, courses are not based on existing lecturers but based on developments and knowledge needs in art research in an art college. So there is no substitute for courses that are considered unethical if the lecturer of the course is still there. So, the course replacement is done after the lecturer dies. That happened because the courses were made not based on research-based learning designs.

3. Making a course is not based on learning the course. This method will cause overlaps between the existing courses. Making courses has not used the overall evaluation method of the subjects to be made. Thus, courses are not made based on the design of learning, which is to achieve effective and efficient learning goals.

4. Based on messages from the government or government policy, curriculum issues must exist. That was caused by the gap between bureaucrats and academics in compiling the curriculum. Not to mention the prominence of policies that are political so that these policies reduce the values and goals of education. That makes the curriculum of learning based on policy often change. Curriculum changes are based on government policy, not based on learning research. The curriculum is made without the involvement of art experts. Although it involves art experts, the decision on the curriculum does not touch on the problems faced by the art college, because the association of lecturers in the pure arts field is still weak and not yet active. Decisions are based on the needs of the art college concerned.

5. Based on the validity period, the curriculum must be changed every four years. Curriculum changes are not based on evaluation and research, but changes are made based on government policies and desires or simply make changes without regard to aspects that are the basis of change and development.

6. Learning culture is still oriented towards lecture material, but teaching is not oriented towards learning objectives effectively and efficiently. By making a learning design in stages as done by Dick and Carey and also M. Atwi Suparman in the Modern Instructional Design book, learning can proceed as it should.

7. Efforts to raise awareness of learning require learning models in the form of learning materials that must be met by a lecturer in learning, such as learning books, lecturer manuals, and student manuals. As part of the learning process, a teacher must be fulfilled.

8. Efforts to raise awareness that learning requires a foundation of research in developing learning models. The aim is that lecture material becomes part of the development of art-science that can contribute to the development of art in socio-cultural realities.
9. Learning activities become a blend of learning and art for lecturers to improve competence and learning to be more comprehensive in lecturing activities. It makes art design and learning the integrity of art, as part of human life in social realities, and not formalistic. It can also open up possibilities in the learning process in art lectures.

10. Art colleges can foster a paradigm of thinking that art or art can develop together with educational technology. Educational technology is part of the art process. Educational technology is not an educational formalism, but science that can enrich the development of art in the contextual life of social, cultural reality. The need to interact with each other, not reduce or eliminate one another, as a form of openness of knowledge.

\section{CONCLUSIONS}

Research and development of learning models conducted produce models and products of learning materials for painting. The learning model as a form of stages in the learning of painting which has so far been based on the habits of lecturers teaching painting, for that learning model can improve the learning process of art courses because it is equipped with learning materials as part of the learning model.

Products that can be used as a reference in painting classes, as a learning process based on learning objectives, not only on learning material, so that learning runs effectively and efficiently. Learning materials are complemented by lecturer manuals and student guides for attending the Art course. Thus, the study of Painting provides knowledge about the sociocultural reality related to the mastery of the material, concepts, and methods of painting. Learning objectives will be easily achieved, in line with the Indonesian National Qualification Framework (KKNI) in determining the level of student ability, that is undergraduate students.

Learning objectives as a basis for determining learning activities will make it easier for lecturers to carry out lectures. It was obtained from a lecturer to be able to know the stages in learning when giving lecture material. Thus, it will be known indicators of student success. Assessing following the learning objectives makes will be more objective and improve students' abilities. Equipped with student guides during the lecture, students also know what needs to be done.

Preparing lecture material and teaching methods refer to learning systems that are appropriate to the learning objectives, not based on learning material. The lecture process begins with preparation related to lectures, preparing lecturers and lecturer guidelines, student guides, and textbooks.

Lectures are better prepared with learning material, and ready for changes according to their development. Besides, in making learning materials research models and learning materials are needed so that learning designs can produce learning materials that are better because they have gone through stages and formative evaluations to achieve the desired learning goals. Every semester the lecturer researches the learning process of the course that is following the vision and mission of the IKJ fine arts. 
The development of this learning model will be the beginning of a gradual change in the paradigm of the thinking of art colleges. The paradigm changes are as follows.

1) Art colleges give birth to formalistic art scholars and artists who have the capacity as an art graduate. In contrast, universities do not produce artists in a simple sense that does not have a conceptual or methodological basis.

2) Teaching courses are based on the ability of artists to teach the courses they teach. The presence of the course was caused by the lecturers still being there. Even though a change in subject is needed, it seems unethical if the lecturer in question has not passed away. After the lecturer who took the subject passed away, the change of subject was made. Instead, make a course not based on learning design.

3) The request of the senior lecturer to make the course is done so that they can teach the course even though it overlaps with other courses. The course will make the curriculum not based on learning design to achieve effective and efficient learning goals.

4) Based on messages from the government or government policy, there is a problem that the curriculum has not been completed. That was caused by the gap between the bureaucracy and academics in compiling the curriculum. Not to mention political policies that reduce the value of education that must be put forward. The learning curriculum is based on policies that change frequently. Curriculum changes are based on government policy, not based on learning research. The curriculum is made not to involve art experts. Although it involved art experts, the decision did not touch on the problems faced by the art college. That is caused by the weakness and not the active-active association of pure art lecturers. Decisions are based on the needs of the art college concerned.

5) Based on the validity period, the curriculum must change every four years. Curriculum changes are not based on evaluation and research, changes are made based on government policies and desires or just make changes, without paying attention to aspects that are the basis of change.

6) The teaching culture that is applied is not to the lecture material, but how the lecture material can achieve the learning objectives effectively and efficiently. By creating learning designs in stages as did Dick and Carey and also Muhammad Atwi Suparman in the book Modern Instructional Design makes learning run as it should.

7) Efforts to raise awareness that teaching requires learning models in the form of learning materials that must be fulfilled by a lecturer in teaching courses that he needs to require learning books, lecturer manuals, and student manuals. The books become part of the learning process that must be fulfilled as a teacher.

8) Efforts to foster awareness that teaching requires a research foundation in developing learning models so that lecture material does indeed become part of the development of art-science that can be a contribution to the development of art in socio-cultural realities.

9) Teaching activities are a combination of teaching and art to improve competence and become more comprehensive in the lecture process. Making art designs and learning produces the integrity of art as part of human life in social realities and is not formalistic and opens up possibilities in the learning process in art lectures.

10) Art colleges can foster a paradigm of thinking that art or art can develop because educational technology is part of the art process. Educational technology is not formalism in education, but science that enriches the development of art in the context of life, socio-cultural reality. The need to interact with one another, not to reduce or eliminate one another as a form of openness of knowledge.

\section{REFERENCES}

Alquran. (1971). Khadim al Haramain asy Syarifain. Raja Fahd, Arab Saudi.

Alfan, Muhammad. (2013). Pengantar Filsafat Nilai. Bandung: Penerbit Pustaka Setia.

Anwar, Chairul. (2017). Teori-teori Pendidikan Klasik hingga Kontemporer. Yogyakarta: Penerbit IRCISoD.

Sucitra, I Gede Arya. (2013). Pengetahuan Bahan Lukisan. Yogyakarta: Penerbit ISI.

Borg, Walter R., Gall Meredith, and Gall Joyce P. (2007). Education Research. United State of America: Penerbit Person.

Dewantara, Ki Hadjar. (1977). Pendidikan dan Kebudayaan. Yogyakarta: Penerbit Majelis Luhur Persatuan Taman Siswa.

Dick, Walter dan Carey. (2009). The Systematic Design of Instruction. United States of America: Pearson.

Direktorat Akademik, Direktrorat Jenderal Pendidikan Tinggi Departemen Pendidikan Nasional.

Gagne, Robert M. (1977). The Conditions of Learning and Theory of Instruction. Florida: College Publishing.

Gredler, Margaret E. (2011). Learning and Instruction. Jakarta: Kencana Prenada Media.

Jenks, Chris. (2013). Culture Study Kebudayaan. Yogyakarta: Pustaka Pelajar.

Mayer, Richard E. (2008). Learning and Instruction. United States of America: Pearson.

Richey, Rita C. (2011). The Instructional Design Knowledge Base. Routledge Published New York. 